\title{
A review of the management of single-suture craniosynostosis, past, present, and future
}

\author{
JNSPG 75th Anniversary Invited Review Article
}

Mark R. Proctor, MD, ${ }^{1}$ and John G. Meara, MD, DMD, MBA²

Departments of ${ }^{1}$ Neurosurgery and ${ }^{2}$ Plastic and Oral Surgery, Boston Children's Hospital, Boston, Massachusetts

BACKGROUND Craniosynostosis is a condition in which 2 or more of the skull bones fuse prematurely. The spectrum of the disorder most commonly involves the closure of a single suture in the skull, but it can also involve syndromic diagnoses in which multiple skull bones and/or bones outside of the cranium are affected. Craniosynostosis can result in cosmetic deformity as well as potential limitations in brain growth and development, and the neurocognitive impact of the condition is just starting to be studied more thoroughly. Our knowledge regarding the genetics of this condition has also evolved substantially. In this review, the authors explore the medical and surgical advancements in understanding and treating this condition over the past century, with a focus on how the diagnosis and treatment have evolved.

METHODS In this review article, the authors, who are the leaders of a craniofacial team at a major academic pediatric hospital, focus on single-suture craniosynostosis (SSC) affecting the 6 major cranial sutures and discuss the evolution of the treatment of SSC from its early history in modern medicine through the current state of the art and future trends. This discussion is based on the authors' broad experience and a comprehensive review of the literature.

SUMMARY The management of SSC has evolved substantially over the past 100 years. There have been major advances in technology and medical knowledge that have allowed for safer treatment of this condition through the use of newer techniques and technologies in the fields of surgery, anesthesia, and critical care. The use of less invasive surgical techniques along with other innovations has led to improved outcomes in SSC patients. The future of SSC treatment will likely be guided by elucidation of the causes of neurocognitive delay in these children and assessment of how the timing and type of surgery can mitigate adverse outcomes.

https://thejns.org/doi/abs/10.3171/2019.7.PEDS18585

KEYWORDS craniosynostosis; craniofacial; endoscopic; anesthesia; cosmetic; cognitive

$\mathrm{T}$ HE human skull is similar to other mammalian skulls; however, it has been adapted for certain unique characteristics of our species. These adaptations include our large brains, which could not fit through the pelvis if allowed to grow to full maturity, and our upright posture, which causes the weight of the human fetus to rest on the female pelvic outlet rather than the abdominal wall. As such, in humans, unlike other mammalian species, gestational pregnancy ends well before significant brain maturity has been achieved. As a result, much of our brain growth occurs over the first 1 to 2 years of life, corresponding to our ability to ambulate, obtain language skills, and otherwise develop into the unique creatures we are, during our early formative years. It is this complete dependency on others early in life that has led to the socialization of the human species as we know it.

\section{Embryology and Genetics Review}

The calvarial vault of the human skull forms as a result of a complex set of processes. The regions of the skull above the mendosal suture, at the midpoint of the occipital bone, are formed by membranous bone formation, a process unique to the skull. ${ }^{40}$ Below this region, endochondral bone formation is the primary process. ${ }^{27}$

The cranial sutures work as the junctions of the mem- 


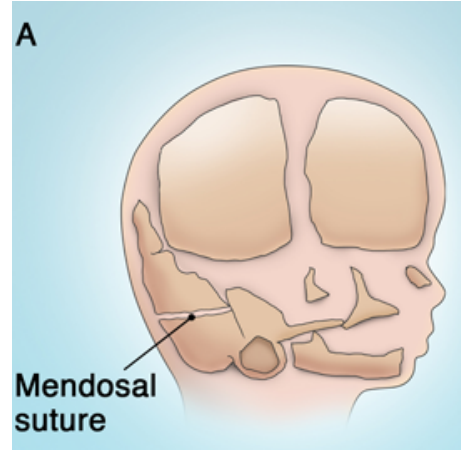

12 week gestation

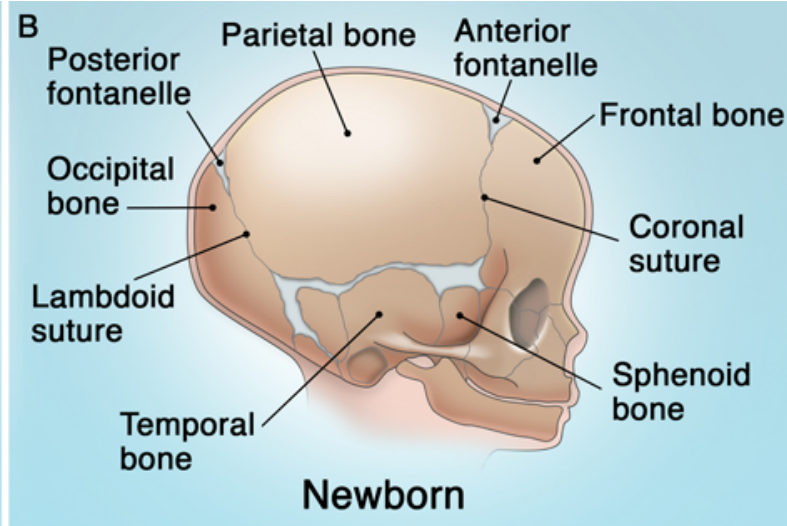

FIG. 1. A: Lateral view of membranous formation of the skull early in gestation. Note the mendosal suture, in the midportion of the occipital bone, which represents the embryological divide between membranous bone formation above and endochondral skull growth below. In most individuals the mendosal suture is fused by full gestation. B: Similar view at full gestation showing normal lateral skull anatomy. Copyright Mark Proctor. Used with permission. branous plates and serve as the growth centers of the skull. ${ }^{34}$ As the brain increases in volume, the plates are pushed apart, and new bone is rapidly generated by the sutures. ${ }^{46}$ Membranous bone formation is regulated by a complex set of genetic processes, with the common mechanism for craniosynostosis involving upregulated osteoblastic activity and downregulated osteoclastic activity and leading to overgrowth and fusion of the bone at the cranial sutures during gestation at a point when apoptosis should have occurred. ${ }^{27}$

Craniosynostosis is a condition that affects the membranous portions of the skull, causing premature fusion of one or multiple cranial sutures. The base of the skull, under the embryological dividing line called the mendosal suture, can also be affected by abnormal growth, such as in achondroplasia and other types of skeletal dysplasia, but this process is distinct from synostosis. ${ }^{20}$ In this review, we focus on single-suture craniosynostosis (SSC) affecting the 6 major cranial sutures (Fig. 1). Craniosynostosis occurs on average in 1 child out of 2500 live births. ${ }^{50}$ As previously discussed, it appears that the abnormal closure of the suture is a consequence of a genetic predisposition, although other theories have been espoused. ${ }^{20,40,41}$

\section{Growth Patterns of the Skull}

An overly simplistic but useful way of imagining head growth is to think about the skull as a balloon, being inflated by the brain, which would be analogous to the air within a balloon. As the brain grows, it pushes the bones apart in a typical oblong fashion, and this happens in such a way that the growth of the brain and its contents is exactly matched by new bone growth at the sutures ${ }^{46}$ Any condition that leads to overgrowth of the brain, for instance, hydrocephalus, causes a disruption of this homeostasis. In this condition, the bone growth cannot keep pace with the brain growth, and the sutures are splayed. Similarly, undergrowth of the brain, for instance, secondary to a perinatal stroke, can cause the loss of outward growth of the brain and lead to a subsequent fusion of the bone plates (usually referred to as secondary craniosynostosis).
Primary craniosynostosis is the pathologic fusion of one or more cranial sutures in such a fashion that the brain growth is limited at some sutures and overcompensated for at the other cranial sutures. In 1851, Virchow stated that normal skull growth is perpendicular to the sutures, and pathological growth in the setting of synostosis occurs parallel to the fused suture. ${ }^{48}$ While this theory is overly simplistic mechanistically, it is a useful way to understand and predict the dysmorphology associated with craniosynostosis. In another theory, espoused by Moss, the primary etiology is attributed to abnormal development of the cranial base that leads to a secondary effect on the corresponding suture through the dural attachment, an elegant concept but one that does not completely reflect the morphological outcomes. ${ }^{42}$ Common deformities associated with craniosynostosis are outlined in Fig. 2.

\section{Rationale for Treatment}

SSC is almost never a life-threatening condition. It is likely that many children could live a relatively normal life without any intervention. The rationale for treatment falls into 2 categories: correction and prevention of cosmetic deformity and prevention of abnormal brain development.

\section{Cosmetic Deformity}

Since most children with SSC present with cosmetic deformity, it is clear that there is a significant concern to the family and the patient's medical providers. For many of these patients, if the condition is left untreated, the deformity will be noticeable as they get older and could be a source of psychological concern for the patient and family. Generally speaking, the deformity noticed at birth will progress through the rapid growth of the brain, during the first 6 to 9 months of life. There is a misconception that the deformity continues to worsen over the course of a lifetime. In fact, since the head is approximately $25 \%$ of the body mass in infancy, the deformity tends to be relatively more noticeable during this period, whereas in adulthood, when the head is approximately $9 \%$ to $10 \%$ of the body mass, the same cosmetic deformity is less noticeable. ${ }^{25}$ 


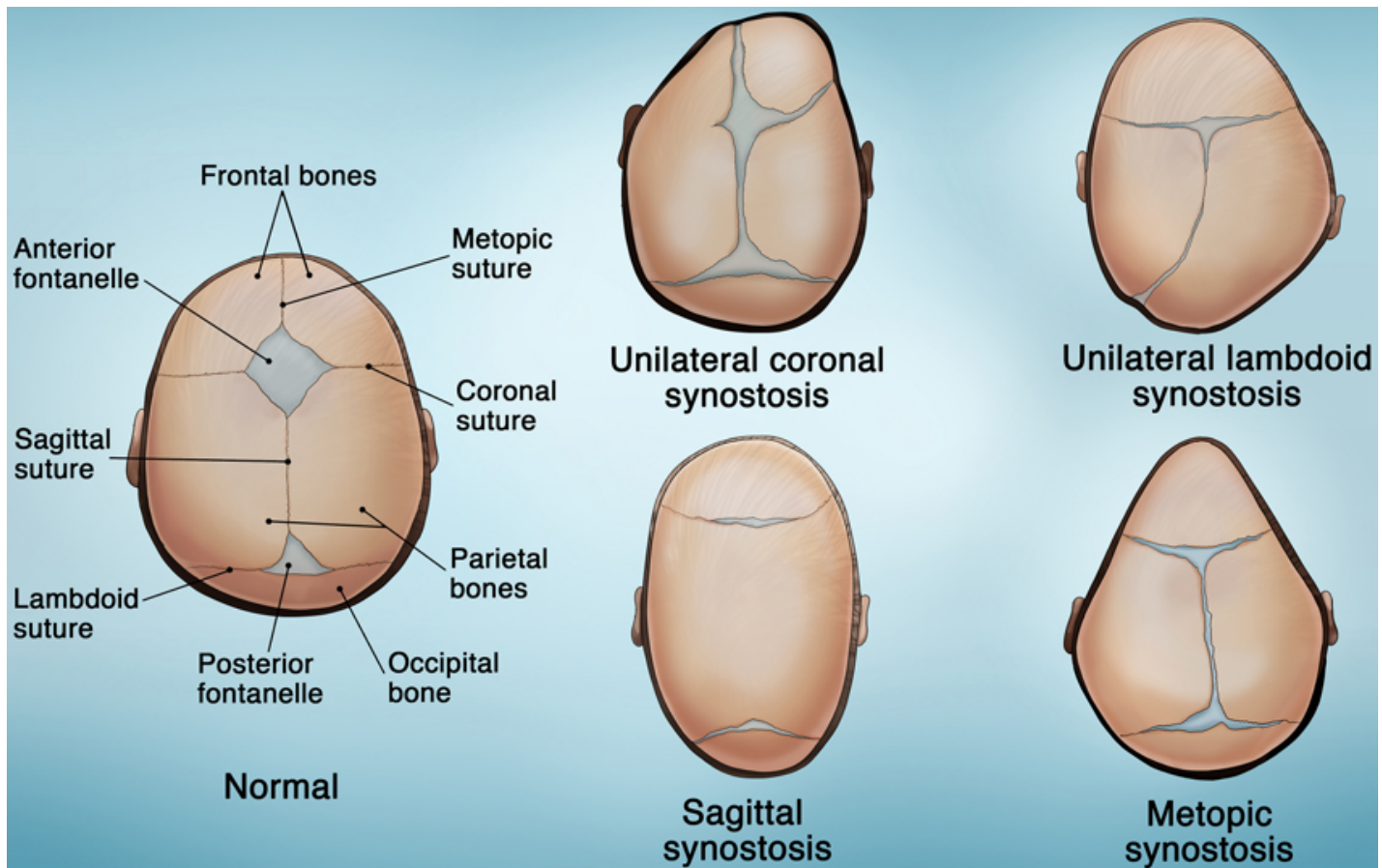

FIG. 2. Bird's-eye view of normal skull anatomy and the 4 major forms of SSC. Copyright Mark Proctor. Used with permission.

This is not a rationale to avoid surgery, but for families who are undecided about the intervention and concerned about worsening cosmetic appearance, they can be reassured that the cranial dysmorphology does not progress in adulthood and may become relatively less apparent. ${ }^{1}$

\section{Brain Development}

Brain and cognitive development and executive functions in the setting of craniosynostosis are much less well understood than the cosmetic issues and represent important areas for future research in craniofacial surgery. Increasingly, routine neurodevelopmental testing is recommended to screen patients with SSC. ${ }^{33,59,62}$ Early cognitive research has shown that compared with unaffected controls, patients with isolated SSC had lower scores on the Bayley Scale of Infant Development II (BSID II) and on the mental and psychomotor developmental indices (MDI and PDI). In SSC patients, MDI scores were two-thirds of a standard deviation below average, and PDI scores were approximately one-third of a standard deviation below the normative mean. ${ }^{62}$

Several studies have been performed to investigate increased reports of cognitive impairment in SSC, and their results suggest that the occurrence of cognitive impairment is directly related to cranial deformity. ${ }^{59}$ Among all the types of SSC, patients with metopic synostosis experience the highest percentage of neurodevelopmental issues. ${ }^{5,45,58-60}$ Many patients with unilateral coronal synostosis have been reported to experience problems with intelligence, speech, learning, and behavior. ${ }^{8,59}$ Additionally, there is a significant lack of clarity about whether or not the age at surgery and the type of surgery have an effect on the neurocognitive outcomes. The literature has many conflicting results on this point, and it is likely that over the upcoming decades there will be better understanding of the effects of timing of surgery on SSC treatment. ${ }^{4,53,59,61,62}$

\section{Treatment}

The singular challenge for craniofacial surgeons is that synostosis repair, even for a single suture, can be a large operation in a very small child. There are constant attempts to minimize the invasiveness of the techniques, determine the optimal age of surgery, and optimize the use of anesthetics and blood conservation techniques. As such, the treatment of craniosynostosis has gone through interesting cycles over time. In the early history of SSC treatment, the operations focused on removing the fused suture, without major surgical reconstruction. Due to inadequate early results, the surgical approach evolved into a much more major operation, generally referred to as cranial vault reconstruction. Over the past 2 decades, there have been new technological advances that have changed the way we are able to treat this condition. These include minimally invasive surgical releases of the fused sutures followed by adjuvant therapy; refinements to cranial vault reconstruction and the use of new fixation devices; new techniques to expand the bones, such as distraction devices and springs; and the application of virtual planning protocols.

\section{Historical Perspective}

Since the first description of a surgical correction of craniosynostosis by Lane in 1892, various techniques have fallen in and out of favor. ${ }^{10,31}$ Initially, high rates of mortality caused surgeons to abandon the procedure altogether. ${ }^{10}$ However, surgical treatment gradually resurfaced, mostly 
in the form of strip craniectomy and removal of the affected suture. ${ }^{10,19}$ The rate of blood transfusion was very high, but the patients tended to fare well with the operation. However, surgeons found that this approach frequently resulted in reclosure of the suture, inadequate correction, and unacceptable cosmetic results. ${ }^{10}$

\section{Evolution of Modern Treatments}

Through advancements in diagnostic capabilities, improvements in surgical techniques, and improved anesthetic techniques, the surgical management of craniosynostosis reemerged in the mid-20th century. ${ }^{10}$ Most of these surgeries were open strip craniectomies, with various incisions that gave access to the fused suture, direct excision of the fusion, and no adjuvant treatment. ${ }^{10}$ In the last quarter of the 20th century, craniofacial surgery emerged as a distinct specialty. A field that had been dominated only by neurosurgeons evolved into a field where neurosurgeons began to work hand in hand with plastic and craniofacial surgeons, oral maxillofacial surgeons, and anesthesiologists. Societies such as the International Society for Craniofacial Surgery emerged, along with multidisciplinary clinics and teams that included neurosurgeons, plastic surgeons, and oral maxillofacial and dental surgeons, as well as practitioners in other clinical specialties such as speech pathology and neuropsychology. ${ }^{72}$

The French craniofacial surgeon Paul Tessier is widely considered to be the father of modern craniofacial surgery. He expanded the scope of surgical intervention to include cranio-orbital and craniomaxillofacial reconstruction and brought a more reliable and reproducible approach which was quickly popularized and became the standard of care. ${ }^{10,66}$ These operations evolved from a simple release of the affected suture to combined procedures where neurosurgeons would remove the affected bone plates, which would be reconstructed and reapplied in a normal orientation by plastic surgeons. In the early days, these lengthy operations were associated with prolonged stays in the intensive care unit, high rates of blood transfusion, and high rates of complications. Over time, refinements made to these operations through the use of new technologies, such as titanium and, subsequently, absorbable plating systems to provide rigid bony fixation, made them much safer, with fewer complications and improved outcomes. These procedures are now widely accepted operations and are performed at all major craniofacial centers. However, over time it has become clear that these operations are not perfect. Even with these major operations and with results at the completion of surgery that appear normal, regression or relapse requiring reoperation often occurs due to the need for treatment of the underlying genetic basis of the condition and the lack of control of future growth after removal of large sections of the cranial bones. ${ }^{64}$

As a result of the discoveries over time of the fallibilities of the major operations, several groups began to apply new technologies to the treatment strategies in an attempt to minimize the risks and improve the outcomes. In the 1990s, Drs. Barone and Jimenez described their experience with an innovative technique combining the technology of minimally invasive endoscopic surgery with postoperative orthotic therapy.,26,52 The endoscope was used to perform the traditional strip craniectomy by using small incisions with minimal blood loss. ${ }^{52}$ Additionally, this allowed for minimal tissue disruption, and the bone generating dura and periosteum were almost untouched. Postoperatively, the orthosis helped to direct skull growth in the desired direction. ${ }^{52}$ The directed growth of the brain and the skull prevented the rapid refusion of the sutures that had been seen in the past. ${ }^{26,51,52,72}$

The work with endoscopic surgery by this pioneering group was the platform from which many other advanced technologies emerged. As it became clear that suture release could be a successful technique as long as refusion of the sutures was avoided, other technologies were applied to mitigate the need for postoperative helmet use. ${ }^{10} \mathrm{Sev}$ eral groups used intracranial springs as the engine to push apart the bones and avoid refusion before the correction occurred. ${ }^{10,15,76}$ Other groups implanted distractor devices to push the bones apart in a more controlled fashion, with the distractor exiting the skull requiring subsequent daily turning for 1-2 months to activate the device and separate the 2 bony segments..$^{10,65,75}$ Compared to the use of the helmet, the distraction osteogenesis technique involves a subsequent operation to remove the devices. Therefore, the use of distraction devices or springs has led to the evolution of the treatment of SCC into a staged surgical approach.

Neurosurgeons at modern craniofacial centers must be familiar with all of these techniques. Realistically speaking, there is no single technique that is ideal for every patient. The appropriate age at the time of surgery for endoscopic approaches is 3-4 months, but for the open cranial vault procedures it can pushed to 6-12 months. ${ }^{2,7,9,51,52}$ The appropriate technique will be dictated by the age of the patients at time of presentation; the availability of the adjuvant therapy, such as helmets, springs, and distractors; the capabilities of a multidisciplinary team to handle such conditions; and family and surgeon preference.

The evolution of these techniques for the 4 forms of SSC are specifically discussed in the next sections.

\section{Sagittal Synostosis}

Sagittal synostosis is the most common form of craniosynostosis. It results in scaphocephaly or dolichocephaly and accounts for $40 \%$ to $60 \%$ of all nonsyndromic craniosynostosis patients. ${ }^{23,29}$ With respect to sex, male patients outnumber females 4 to $1 . .^{21,47}$ Recently, advancements in the field of molecular genetics have led to the elucidation by researchers of some of the genetic causes for sagittal synostosis, which may one day yield explanations for its frequency and sex predisposition. . $8,30,67,68^{2}$

Treatment of sagittal synostosis has undergone a cycle from open wide-vertex suturectomy to the many described techniques for cranial vault reconstruction to minimally invasive endoscopic approaches with the use of helmets, springs, and distractors (Fig. 3).

\section{Metopic Synostosis}

The metopic suture separates the 2 frontal bones and is normally the first suture to close, starting as early as 3 months, and to fuse completely, by the age of 8 months..$^{69,70,73}$ Metopic synostosis accounts for $10 \%$ to $15 \%$ 

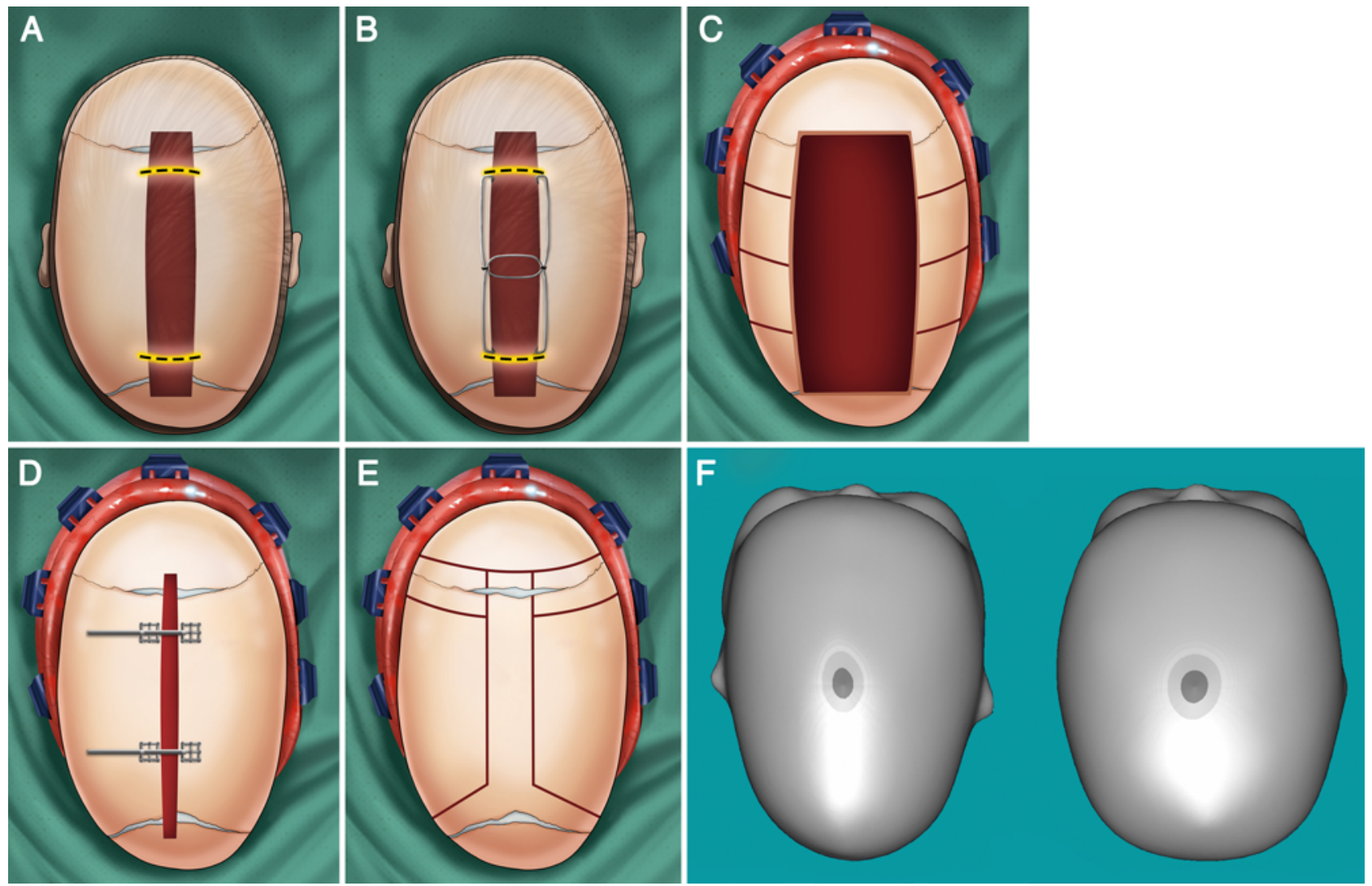

FIG. 3. Major treatment options for sagittal synostosis correction (yellow lines represent incisions). A: Endoscopic strip craniectomy. This form of treatment is generally followed by adjuvant helmet therapy for 6-9 months. B: Craniectomy and spring placement. The springs drive the bones apart and must be surgically removed after 3-4 months. C: Wide-vertex craniotomy along with barrel stave osteotomies. D: Release followed by placement of distractor devices. These are gradually expanded over 6-12 weeks to drive lateral growth, and then the distractors must be surgically removed. E: Bony cuts for cranial vault reconstruction, an operation which has many variations. F: Laser scans used to make cranial helmets. Results before and after endoscopic release and helmet treatment are shown. Copyright Mark Proctor. Used with permission.

of children with craniosynostosis. ${ }^{29,78}$ It results in a trigonocephalic head shape. ${ }^{69}$ Di Rocco et al. reported an increase of $420 \%$ in the incidence of metopic craniosynostosis over a period of 20 years. ${ }^{16,17,57,69}$ However, it is difficult to understand the rationale for the substantial increase in this condition. Some experts feel that the increase in the incidence of metopic craniosynostosis represents a change in the diagnostic criteria leading to higher rates of surgery. As the need for more objective criteria to diagnose trigonocephaly has increased, some authors have advocated more objective criteria for the use of surgical treatment, such as measurement of the interfrontal angle, which can be directly measured from a scan, and for which the operative threshold is $118^{\circ}$ (Fig. 4). ${ }^{3}$ If the angle exceeds $118^{\circ}$, in many cases, this value can be considered as a normal variant for the interfrontal angle.

Treatment options for metopic synostosis include either open cranial vault reconstruction or minimally invasive endoscopic strip craniectomy followed by helmet therapy. Both techniques have similar esthetic results (Fig. 5). ${ }^{43}$

\section{Unilateral Coronal Synostosis}

Unilateral coronal synostosis (UCS) is the second most common form of craniosynostosis, accounting for $20 \%$ to $35 \%$ of nonsyndromic craniosynostosis patients. ${ }^{29}$ There is also a sex predilection, as female patients outnumber males 3 to 2. 21,47 Unlike sagittal and metopic synostosis, UCS can lead to significant deformity by altering the regular growth of the adjacent cranial bones.6, ${ }^{6,35,36}$ These effects on the skull base and the sphenoid bone lead to a pathognomonic finding, known as the "harlequin" sign, on a plain anteroposterior (AP) skull radiograph. The deformity includes frontal plagiocephaly with retrusion of the forehead and the superior orbital rim on the affected side and frontal bossing on the contralateral forehead and lateral orbital rim. Nasal deformity with deviation of the bony nasal dorsum to the affected side and orbital asymmetry are also hallmarks of UCS. ${ }^{6,11}$ Ocular manifestations include aniso-astigmatism, ocular torticollis, and amblyopia. ${ }^{6}$ Strabismus is also common in patients with UCS, with rates of $39 \%$ to $91 \% .13,22,56$

The primary treatment options for UCS include endoscopic surgery followed by helmet therapy and release operations along with springs or distractors and frontoorbital advancement procedures. Interestingly, early operation seems to increase beneficial outcomes for correction of orbital dysmorphology, ocular abnormalities, and facial 


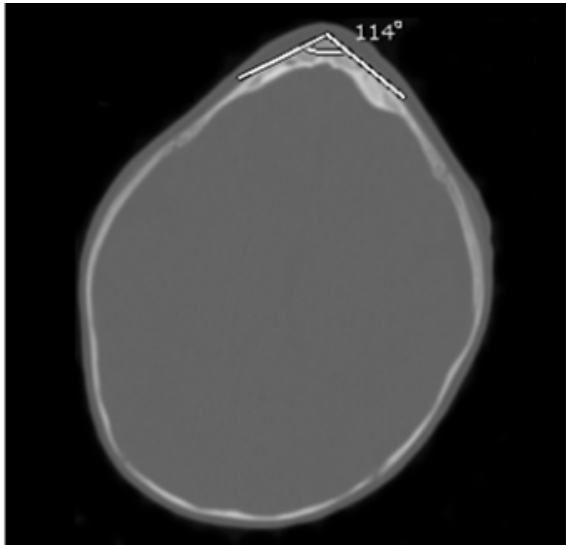

FIG. 4. CT scan demonstrating the interfrontal angle, an accurate and objective way of measuring the degree of trigonocephaly. Generally an angle $<118^{\circ}$ would be considered an indication for surgical correction.

asymmetry. ${ }^{52,63}$ This is likely due to the early intervention and the fact that the periorbita is not detached from the bone, so that as the improvement in the bone is achieved the orbital muscles are stretched (Fig. 5). ${ }^{37,38,52}$

\section{Unilateral Lambdoid Synostosis}

Unilateral lambdoid synostosis is a rare form of craniosynostosis, accounting for $1 \%$ to $5 \%$ of the craniosynostosis population. ${ }^{54}$ The biggest dilemma here is diagnostic, as this form of syntosis should be distinguished from deformational posterior plagiocephaly caused by prolonged external pressure on the normal skull. ${ }^{54}$ Distinguishing phenotypic features include ipsilateral shifting of the ear inferiorly and posteriorly, ipsilateral occipito-mastoid bulge, and compensatory contralateral parietal and frontal bossing leading to a trapezoid head shape, with the constellation of findings referred to as a "windswept" appearance (Fig. 6). ${ }^{24,54}$ The use of open and endoscopic techniques has been described for correction.
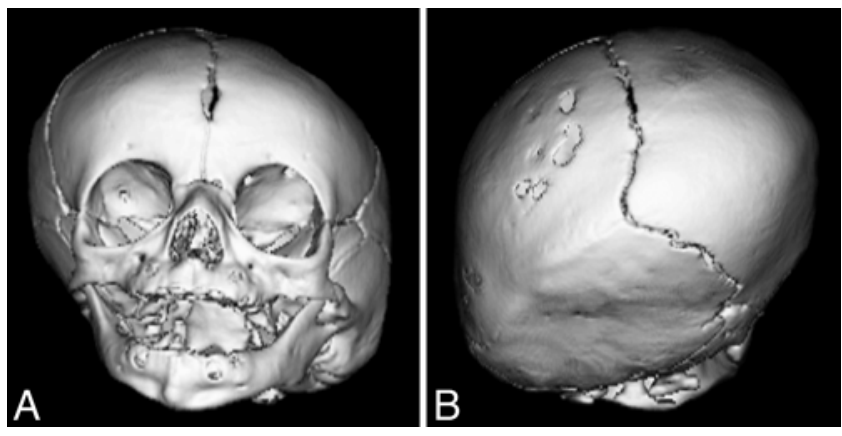

FIG. 6. 3D CT scan revealing the major deformities in lambdoid synostosis seen from the anterior $(\mathbf{A})$ and posterior $(\mathbf{B})$ views. Note the ipsilateral flattening and mastoid bulge along with the contralateral "windswept" appearance of the skull.

\section{Future Trends}

It is clear that surgeons will continue to refine techniques to maximize cosmetic outcomes and minimize surgical trauma in patients undergoing treatment for SSC. Although there is always room for improvement in esthetic outcomes, many craniofacial surgeons believe that the outcomes are now at the point where the optimization of brain development in patients with SSC should be the principal focus in the upcoming decades. There are several factors that may affect neurocognitive optimization, and these sometimes align and sometimes compete with anesthetic and cosmetic concerns.

\section{Anesthetic Considerations}

The timing of surgical intervention relative to anesthetic safety is controversial. Advantages of early surgical intervention include increased malleability of the softer bone, earlier release of potential pressure on the brain, and the benefit of the rapid brain growth very early in life in promoting growth of the cranial vault. However, early intervention entails the performance of the operation and
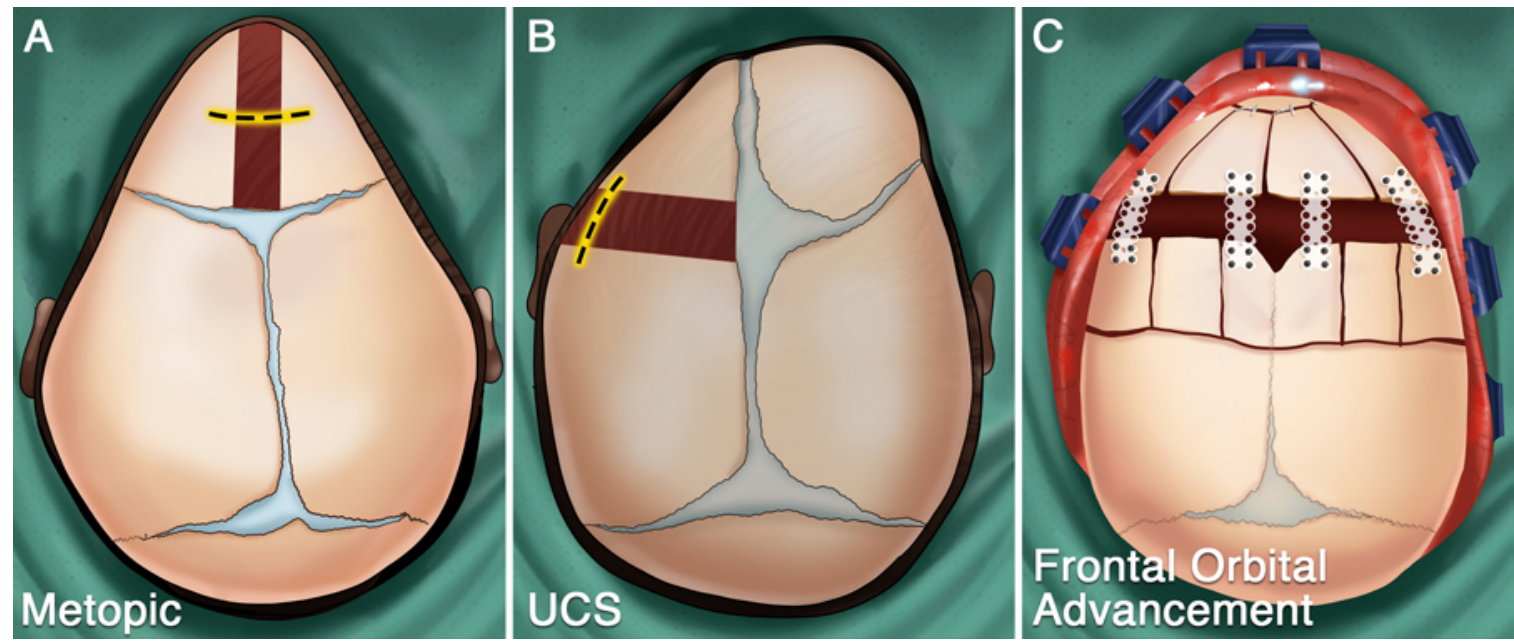

FIG. 5. Correction of metopic synostosis and unilateral coronal synostosis (UCS) (yellow lines represent incisions). A and B: Bony removal for endoscopic treatment. C: Fronto-orbital advancement operation, which would be the same corrective procedure for either deformity. Copyright Mark Proctor. Used with permission. 

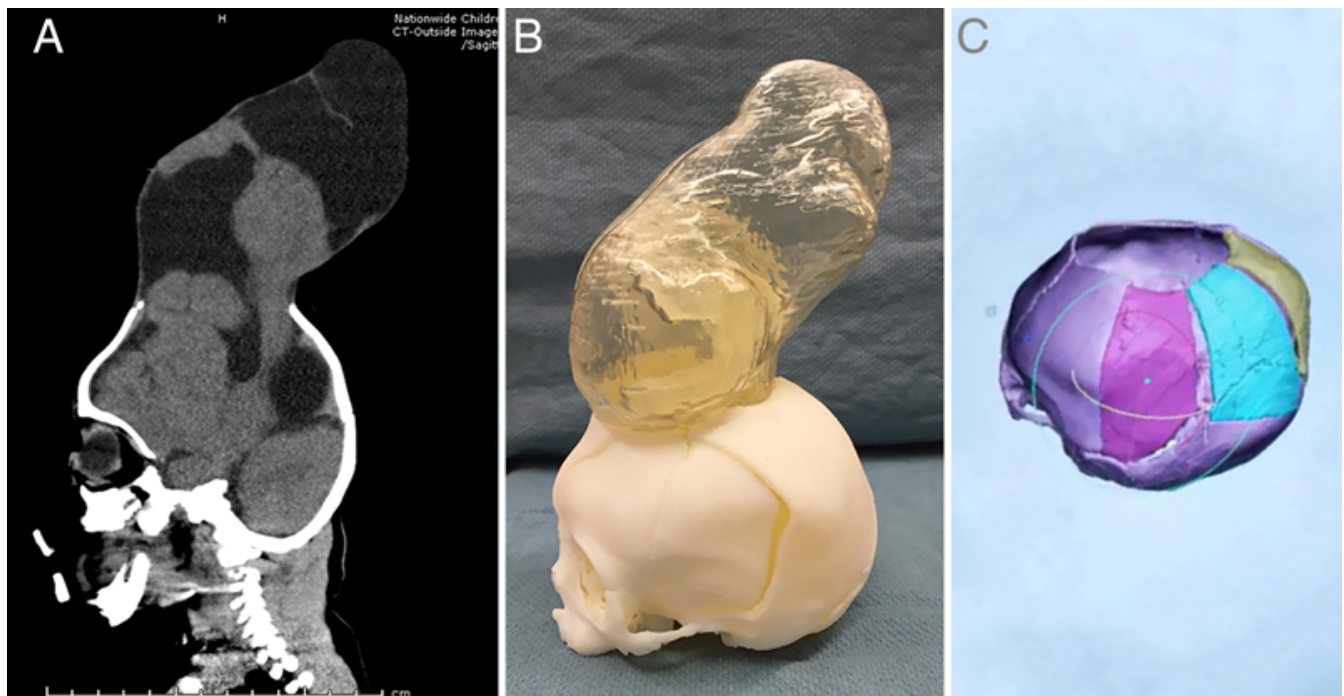

FIG. 7. The case of a complex encephalocele for which $3 \mathrm{D}$ models and computer simulations were used to assist in surgical planning. A: Planning CT, showing a sagittal view with the complex encephalocele emanating from the vertex. B: 3D model created for surgical planning. Several models were made to practice the bone cuts that were performed at surgery. C: A computer was used to calculate the increase in intracranial volume necessary to replace all of the brain back within the skull, and which bone cuts would be needed to achieve these volume increases. The planned procedure was then successfully accomplished at surgery.

anesthesia exposure in a smaller child at a vulnerable point in neurodevelopment, with increased risk of blood loss and concerns for the neurodevelopmental impact from anesthesia. ${ }^{18}$ Comparing endoscopic techniques with cranial vault reconstruction, there is a balance of a short anesthesia duration at 3-4 months of age for the former versus a longer anesthesia duration in a child 6-12 months of age..$^{18}$

The optimal timing relative to the risk of anesthesia remains unclear, although current data for children younger than 1 year lean toward reducing the total time under anesthesia and the number of exposures to general anesthesia. ${ }^{18}$ In a randomized clinical trial that focused on the timing of surgery in children and the related potential neurotoxicity, the neurocognitive impact of a 1-hour general anesthetic on infants younger than 6 months was investigated. ${ }^{14}$ No decrement in neurocognitive functions was found 2 or 5 years later in the young patients who underwent this surgery. ${ }^{14,39}$ These study outcomes may reassure surgeons and families that a brief period of anesthesia in young infants does not impact cognitive outcomes. Another study reported that exposure of children to general anesthesia before the age of 3 years is not associated with lower IQ. ${ }^{71}$ Additionally, single exposures are less associated with neuropsychological deficits, whereas multiple exposures are associated with a modest decrease in processing speed and fine-motor coordination. ${ }^{71,77}$ Parents also reported that children multiply exposed to anesthesia have more difficulties with behavior and reading. Based on these findings, we would predict that in the first year of life infants undergoing a shorter-duration endoscopic approach with a single anesthesia exposure would be less vulnerable to neurocognitive decline than those undergoing longer and more extensive cranial vault reconstruction or techniques that require a second anesthetic.

The improvement in anesthetic techniques is beyond the scope of this review; however, there have been ma- jor advances, particularly related to blood conservation techniques. The use of antifibrinolytic agents such as tranexamic acid has become prevalent in craniofacial surgery, as well as the progressive use of cell saver, induced hypotension, preoperative erythropoietin (EPO), and improved surgical techniques in order to minimize blood loss. ${ }^{22,49,74}$

\section{Follow-Up Considerations}

It is absolutely clear that children with SSC remain at risk for problems with brain growth and development at least through the first several years of life. Although it is widely believed that cranial sutures fuse at 1 to 2 years of life, they are in fact anatomically open until the completion of all skeletal growth at the completion of puberty. This misconception regarding the age of suture fusion comes from the fact that the majority of intracranial growth is completed by 2 to 3 years of age, but physicians must understand that some brain growth continues for several more years. ${ }^{25}$ Therefore, patients with SSC must be followed by a multidisciplinary craniofacial clinic until at least 6 years of age..$^{72}$

\section{Minimizing Surgical Trauma}

All surgical disciplines have attempted to minimize surgical trauma through the evolution of both surgical and anesthetic techniques. One exciting technological innovation that has become more prevalent in the field of craniofacial surgery is the use of virtual surgical planning. Many centers now use either virtual or actual 3D printed models to visualize and plan the operation for correction of complex deformities (Fig. 7). Although less meaningful for SSC patients, who tend to have stereotypic deformities with which craniofacial surgeons are quite experienced, this technology is invaluable for patients with rare defor- 
mities. In addition, the utility of these new methods in training the next generation of craniofacial surgeons has significant potential..$^{12,44,55}$

\section{Genetics}

The genetic pathophysiology of synostosis is becoming increasingly well understood. ${ }^{68}$ There may come a time when nonsurgical treatment options will be available that are based on a more comprehensive understanding of the genetic etiopathogenesis of craniosynostosis. However, since the condition is in many ways mechanical and the cosmetic outcomes are already determined at the time of birth, genetic manipulations at that point may be too little too late to correct the deformity.

\section{Conclusions}

The field of craniofacial surgery has gone through exciting advances in the past century. We have seen it go from a single technique that was abandoned due to poor surgical indications and high mortality rates to a refined technique that enables us to correct the skull at all ages using a combination of minimally invasive techniques and cranial vault reconstruction operations. The future will be guided by a trend toward minimizing surgical trauma and maximizing neurocognitive outcomes, while preserving excellent cosmetic correction. New technologies such as improved devices for bone fixation and expansion, along with 3D and virtual planning, will contribute to the continued evolution of this field of neurosurgery, and as we gain increasing knowledge of the genetics underlying craniosyntosis, there may come a time when its treatment is no longer a surgical discipline.

\section{Acknowledgments}

The authors would like to thank Ms. Emily Day and Dr. Mohammed Fouda for their excellent assistance in the preparation of this manuscript.

\section{References}

1. Al-Shaqsi S, Zellner E, Ching J, Forrest C, Phillips J: The natural history of cranial morphology in sagittal craniosynostosis. J Craniofac Surg 29:852-855, 2018

2. Anantheswar YN, Venkataramana NK: Pediatric craniofacial surgery for craniosynostosis: our experience and current concepts: Part 1. J Pediatr Neurosci 4:86-99, 2009

3. Anolik RA, Allori AC, Pourtaheri N, Rogers GF, Marcus JR: Objective assessment of the interfrontal angle for severity grading and operative decision-making in metopic synostosis. Plast Reconstr Surg 137:1548-1555, 2016

4. Arnaud E, Renier D, Marchac D: Prognosis for mental function in scaphocephaly. J Neurosurg 83:476-479, 1995

5. Aryan HE, Jandial R, Ozgur BM, Hughes SA, Meltzer HS, Park MS, et al: Surgical correction of metopic synostosis. Childs Nerv Syst 21:392-398, 2005

6. Balaji SM: Unicoronal craniosynostosis and plagiocephaly correction with fronto-orbital bone remodeling and advancement. Ann Maxillofac Surg 7:108-111, 2017

7. Barone CM, Jimenez DF: Endoscopic craniectomy for early correction of craniosynostosis. Plast Reconstr Surg 104:1965-1975, 1999

8. Becker DB, Petersen JD, Kane AA, Cradock MM, Pilgram TK, Marsh JL: Speech, cognitive, and behavioral outcomes in nonsyndromic craniosynostosis. Plast Reconstr Surg 116:400-407, 2005

9. Berry-Candelario J, Ridgway EB, Grondin RT, Rogers GF, Proctor MR: Endoscope-assisted strip craniectomy and postoperative helmet therapy for treatment of craniosynostosis. Neurosurg Focus 31(2):E5, 2011

10. Birgfeld CB, Dufton L, Naumann H, Hopper RA, Gruss JS, Haberkern CM, et al: Safety of open cranial vault surgery for single-suture craniosynostosis: a case for the multidisciplinary team. J Craniofac Surg 26:2052-2058, 2015

11. Bruneteau RJ, Mulliken JB: Frontal plagiocephaly: synostotic, compensational, or deformational. Plast Reconstr Surg 89:21-33, 1992

12. Cho RS, Lopez J, Musavi L, Kachniarz B, Macmillan A, Badiei B, et al: Computer-assisted design and manufacturing assists less experienced surgeons in achieving equivalent outcomes in cranial vault reconstruction. J Craniofac Surg [epub ahead of print], 2019

13. Chung SA, Yun IS, Moon JW, Lee JB: Ophthalmic findings in children with nonsyndromic craniosynostosis treated by expansion cranioplasty. J Craniofac Surg 26:79-83, 2015

14. Davidson AJ, Disma N, de Graaff JC, Withington DE, Dorris L, Bell G, et al: Neurodevelopmental outcome at 2 years of age after general anaesthesia and awake-regional anaesthesia in infancy (GAS): an international multicentre, randomised controlled trial. Lancet 387:239-250, 2016

15. Davis C, Windh P, Lauritzen CG: Adaptation of the cranium to spring cranioplasty forces. Childs Nerv Syst 26:367-371, 2010

16. Di Rocco F, Arnaud E, Meyer P, Sainte-Rose C, Renier D: Focus session on the changing "epidemiology" of craniosynostosis (comparing two quinquennia: 1985-1989 and 2003-2007) and its impact on the daily clinical practice: a review from Necker Enfants Malades. Childs Nerv Syst 25:807-811, 2009

17. Di Rocco F, Arnaud E, Renier D: Evolution in the frequency of nonsyndromic craniosynostosis. J Neurosurg Pediatr 4:21-25, 2009

18. Disma N, O'Leary JD, Loepke AW, Brambrink AM, Becke K, Clausen NG, et al: Anesthesia and the developing brain: a way forward for laboratory and clinical research. Paediatr Anaesth 28:758-763, 2018

19. Faber HK, Towne EB: Early operation in premature cranial synostosis for the prevention of blindness and other sequelae: five case reports with follow-up. J Pediatr 22:286-307, 1943

20. Flaherty K, Singh N, Richtsmeier JT: Understanding craniosynostosis as a growth disorder. Wiley Interdiscip Rev Dev Biol 5:429-459, 2016

21. Garza RM, Khosla RK: Nonsyndromic craniosynostosis. Semin Plast Surg 26:53-63, 2012

22. Goobie SM, Meier PM, Pereira LM, McGowan FX, Prescilla $\mathrm{RP}$, Scharp LA, et al: Efficacy of tranexamic acid in pediatric craniosynostosis surgery: a double-blind, placebo-controlled trial. Anesthesiology 114:862-871, 2011

23. Gupta PC, Foster J, Crowe S, Papay FA, Luciano M, Traboulsi EI: Ophthalmologic findings in patients with nonsyndromic plagiocephaly. J Craniofac Surg 14:529-532, 2003

24. Huang MH, Gruss JS, Clarren SK, Mouradian WE, Cunningham ML, Roberts TS, et al: The differential diagnosis of posterior plagiocephaly: true lambdoid synostosis versus positional molding. Plast Reconstr Surg 98:765-776, 1996

25. Huelke DF: An overview of anatomical considerations of infants and children in the adult world of automobile safety design. Annu Proc Assoc Adv Automot Med 42:93-113, 1998.

26. Jimenez DF, Barone CM, Cartwright CC, Baker L: Early management of craniosynostosis using endoscopic-assisted strip craniectomies and cranial orthotic molding therapy. Pediatrics 110:97-104, 2002 
27. Jin SW, Sim KB, Kim SD: Development and growth of the normal cranial vault: an embryologic review. J Korean Neurosurg Soc 59:192-196, 2016

28. Justice CM, Yagnik G, Kim Y, Peter I, Jabs EW, Erazo M, et al: A genome-wide association study identifies susceptibility loci for nonsyndromic sagittal craniosynostosis near BMP2 and within BBS9. Nat Genet 44:1360-1364, 2012

29. Kalantar-Hormozi H, Abbaszadeh-Kasbi A, Sharifi G, Davai NR, Kalantar-Hormozi A: Incidence of familial craniosynostosis among patients with nonsyndromic craniosynostosis. J Craniofac Surg 30:e514-e517, 2019

30. Komatsu Y, Mishina Y: An epistatic explanation. eLife 5:e21162, 2016

31. Lane L: Pioneer craniectomy for relief of mental imbecility due to premature sutural closure and microcephalus. J Am Med Assoc 18:49-50, 1892

32. Lehman S: Strabismus in craniosynostosis. Curr Opin Ophthalmol 17:432-434, 2006

33. Lekovic GP, Bristol RE, Rekate HL: Cognitive impact of craniosynostosis. Semin Pediatr Neurol 11:305-310, 2004

34. Lenton KA, Nacamuli RP, Wan DC, Helms JA, Longaker MT: Cranial suture biology. Curr Top Dev Biol 66:287-328, 2005

35. Levy RL, Rogers GF, Mulliken JB, Proctor MR, Dagi LR: Astigmatism in unilateral coronal synostosis: incidence and laterality. J AAPOS 11:367-372, 2007

36. Macintosh C, Wall S, Leach C: Strabismus in unicoronal synostosis: ipsilateral or contralateral? J Craniofac Surg 18:465-469, 2007

37. MacKinnon S, Proctor MR, Rogers GF, Meara JG, Whitecross S, Dagi LR: Improving ophthalmic outcomes in children with unilateral coronal synostosis by treatment with endoscopic strip craniectomy and helmet therapy rather than fronto-orbital advancement. J AAPOS 17:259-265, 2013

38. MacKinnon S, Rogers GF, Gregas M, Proctor MR, Mulliken JB, Dagi LR: Treatment of unilateral coronal synostosis by endoscopic strip craniectomy or fronto-orbital advancement: Ophthalmologic findings. J AAPOS 13:155-160, 2009

39. McCann ME, de Graaff JC, Dorris L, Disma N, Withington D, Bell G, et al: Neurodevelopmental outcome at 5 years of age after general anaesthesia or awake-regional anaesthesia in infancy (GAS): an international, multicentre, randomised, controlled equivalence trial. Lancet 393:664-677, 2019

40. Miura T, Perlyn CA, Kinboshi M, Ogihara N, KobayashiMiura M, Morriss-Kay GM, et al: Mechanism of skull suture maintenance and interdigitation. J Anat 215:642-655, 2009

41. Morriss-Kay GM, Wilkie AO: Growth of the normal skull vault and its alteration in craniosynostosis: insights from human genetics and experimental studies. J Anat 207:637-653, 2005

42. Moss ML: Functional anatomy of cranial synostosis. Childs Brain 1:22-33, 1975

43. Nguyen DC, Patel KB, Skolnick GB, Naidoo SD, Huang AH, Smyth MD, et al: Are endoscopic and open treatments of metopic synostosis equivalent in treating trigonocephaly and hypotelorism? J Craniofac Surg 26:129-134, 2015

44. Ni J, Yang B, Li B: Reconstructive operation of nonsyndromic multiple-suture craniosynostosis based on precise virtual plan and prefabricated template. J Craniofac Surg 28:1541-1542, 2017

45. Oi S, Matsumoto S: Trigonocephaly (metopic synostosis). Clinical, surgical and anatomical concepts. Childs Nerv Syst 3:259-265, 1987

46. Pattisapu JV, Gegg CA, Olavarria G, Johnson KK, Ruiz RL, Costello BJ: Craniosynostosis: diagnosis and surgical management. Atlas Oral Maxillofac Surg Clin North Am 18:77-91, 2010

47. Persing JA: MOC-PS(SM) CME article: management consid- erations in the treatment of craniosynostosis. Plast Reconstr Surg 121 (4 Suppl): 1-11, 2008

48. Persing JA, Jane JA, Shaffrey M: Virchow and the pathogenesis of craniosynostosis: a translation of his original work. Plast Reconstr Surg 83:738-742, 1989

49. Pietrini D, Goobie S: Intraoperative management of blood loss during craniosynostosis surgery. Paediatr Anaesth 23:278-284, 2013

50. Poot M: Structural genome variations related to craniosynostosis. Mol Syndromol 10:24-39, 2019

51. Proctor MR: Endoscopic cranial suture release for the treatment of craniosynostosis - is it the future? J Craniofac Surg 23:225-228, 2012

52. Proctor MR: Endoscopic craniosynostosis repair. Transl Pediatr 3:247-258, 2014

53. Renier D: Intracranial pressure in craniosynostosis: pre-and postoperative recordings-correlation with functional results, in Persing JA, Edgerton MT, Jane J (eds): Scientific Foundations and Surgical Treatment of Craniosynostosis. Baltimore: Williams \& Wilkins, 1989, pp 263-269

54. Rhodes JL, Tye GW, Fearon JA: Craniosynostosis of the lambdoid suture. Semin Plast Surg 28:138-143, 2014

55. Rogers-Vizena CR, Sporn SF, Daniels KM, Padwa BL, Weinstock P: Cost-benefit analysis of three-dimensional craniofacial models for midfacial distraction: a pilot study. Cleft Palate Craniofac J 54:612-617, 2017

56. Rosenberg JB, Tepper OM, Medow NB: Strabismus in craniosynostosis. J Pediatr Ophthalmol Strabismus 50:140 148,2013

57. Selber J, Reid RR, Chike-Obi CJ, Sutton LN, Zackai EH, McDonald-McGinn D, et al: The changing epidemiologic spectrum of single-suture synostoses. Plast Reconstr Surg 122:527-533, 2008

58. Shillito J Jr, Matson DD: Craniosynostosis: a review of 519 surgical patients. Pediatrics 41:829-853, 1968

59. Shim KW, Park EK, Kim JS, Kim YO, Kim DS: Neurodevelopmental problems in non-syndromic craniosynostosis. J Korean Neurosurg Soc 59:242-246, 2016

60. Shimoji T, Shimabukuro S, Sugama S, Ochiai Y: Mild trigonocephaly with clinical symptoms: analysis of surgical results in 65 patients. Childs Nerv Syst 18:215-224, 2002

61. Shipster C, Hearst D, Somerville A, Stackhouse J, Hayward $\mathrm{R}$, Wade A: Speech, language, and cognitive development in children with isolated sagittal synostosis. Dev Med Child Neurol 45:34-43, 2003

62. Speltz ML, Kapp-Simon K, Collett B, Keich Y, Gaither R, Cradock MM, et al: Neurodevelopment of infants with single-suture craniosynostosis: presurgery comparisons with case-matched controls. Plast Reconstr Surg 119:1874-1881, 2007

63. Tan SP, Proctor MR, Mulliken JB, Rogers GF: Early frontofacial symmetry after correction of unilateral coronal synostosis: frontoorbital advancement vs endoscopic strip craniectomy and helmet therapy. J Craniofac Surg 24:1190-1194, 2013

64. Taylor JA, Paliga JT, Wes AM, Tahiri Y, Goldstein JA, Whitaker LA, et al: A critical evaluation of long-term aesthetic outcomes of fronto-orbital advancement and cranial vault remodeling in nonsyndromic unicoronal craniosynostosis. Plast Reconstr Surg 135:220-231, 2015

65. Tellado MG, Lema A: Coronal suturectomy through minimal incisions and distraction osteogenesis are enough without other craniotomies for the treatment of plagiocephaly due to coronal synostosis. J Craniofac Surg 20:1975-1977, 2009

66. Tessier P: [Total facial osteotomy. Crouzon's syndrome, Apert's syndrome: oxycephaly, scaphocephaly, turricephaly.] Ann Chir Plast 12:273-286, 1967 (French)

67. Timberlake AT, Choi J, Zaidi S, Lu Q, Nelson-Williams C, Brooks ED, et al: Two locus inheritance of non-syndromic 
midline craniosynostosis via rare SMAD6 and common $B M P 2$ alleles. eLife 5:e20125, 2016

68. Timberlake AT, Persing JA: Genetics of nonsyndromic craniosynostosis. Plast Reconstr Surg 141:1508-1516, 2018

69. van der Meulen J: Metopic synostosis. Childs Nerv Syst 28:1359-1367, 2012

70. Vu HL, Panchal J, Parker EE, Levine NS, Francel P: The timing of physiologic closure of the metopic suture: a review of 159 patients using reconstructed 3D CT scans of the craniofacial region. J Craniofac Surg 12:527-532, 2001

71. Warner DO, Zaccariello MJ, Katusic SK, Schroeder DR, Hanson AC, Schulte PJ, et al: Neuropsychological and behavioral outcomes after exposure of young children to procedures requiring general anesthesia: the Mayo Anesthesia Safety in Kids (MASK) Study. Anesthesiology 129:89-105, 2018

72. Warren SM, Proctor MR, Bartlett SP, Blount JP, Buchman SR, Burnett W, et al: Parameters of care for craniosynostosis: craniofacial and neurologic surgery perspectives. Plast Reconstr Surg 129:731-737, 2012

73. Weinzweig J, Kirschner RE, Farley A, Reiss P, Hunter J, Whitaker LA, et al: Metopic synostosis: defining the temporal sequence of normal suture fusion and differentiating it from synostosis on the basis of computed tomography images. Plast Reconstr Surg 112:1211-1218, 2003

74. White N, Bayliss S, Moore D: Systematic review of interventions for minimizing perioperative blood transfusion for surgery for craniosynostosis. J Craniofac Surg 26:26-36, 2015

75. White N, Evans M, Dover MS, Noons P, Solanki G, Nishikawa $\mathrm{H}$ : Posterior calvarial vault expansion using distraction osteogenesis. Childs Nerv Syst 25:231-236, 2009

76. Windh P, Davis C, Sanger C, Sahlin P, Lauritzen C: Springassisted cranioplasty vs pi-plasty for sagittal synostosis - a long term follow-up study. J Craniofac Surg 19:59-64, 2008

77. Zaccariello MJ, Frank RD, Lee M, Kirsch AC, Schroeder DR, Hanson AC, et al: Patterns of neuropsychological changes after general anaesthesia in young children: secondary analysis of the Mayo Anesthesia Safety in Kids study. Br J Anaesth 122:671-681, 2019

78. Zeiger JS, Beaty TH, Hetmanski JB, Wang H, Scott AF, Kasch L, et al: Genetic and environmental risk factors for sagittal craniosynostosis. J Craniofac Surg 13:602-606, 2002

\section{Disclosures}

The authors report no conflict of interest concerning the materials or methods used in this study or the findings specified in this paper.

\section{Author Contributions}

Conception and design: both authors. Acquisition of data: both authors. Analysis and interpretation of data: both authors. Drafting the article: both authors. Critically revising the article: both authors. Reviewed submitted version of manuscript: both authors. Approved the final version of the manuscript on behalf of both authors: Proctor. Administrative/technical/material support: both authors. Study supervision: Proctor.

\section{Correspondence}

Mark R. Proctor: Boston Children's Hospital, Boston, MA. mark. proctor@childrens.harvard.edu. 